\title{
Quality Improvement of Recycled Aggregate Concrete using Six Sigma DMAIC Methodology
}

\author{
Suhas Vijay Patil \\ Department of Civil Engineering, \\ Manipal Institute of Technology, Manipal Academy of Higher Education, \\ Manipal, 576104, Karnataka, India. \\ Corresponding author: suhaspatil16@gmail.com \\ Balakrishna Rao K. \\ Department of Civil Engineering, \\ Manipal Institute of Technology, Manipal Academy of Higher Education, \\ Manipal, 576104, Karnataka, India. \\ E-mail:kb.rao@manipal.edu \\ Gopinatha Nayak \\ Department of Civil Engineering, \\ Manipal Institute of Technology, Manipal Academy of Higher Education, \\ Manipal, 576104, Karnataka, India. \\ E-mail: nayak.gopinath@manipal.edu
}

(Received February 27, 2020; Accepted August 7, 2020)

\begin{abstract}
Recycled aggregates (RA) are obtained from construction and demolished waste, laboratory crushed concrete and concrete waste at RMC plants. The concrete made from recycled aggregate is known as recycled aggregate concrete. The use of recycled aggregate is very beneficial to the environment in civil works. Its usage also helps in financial saving as the cost of transportation and production energy cost of natural coarse aggregate (NCA) is reduced. In India, the recycled aggregate application in lower grade concrete work is observed. However, the effect of recycled aggregate on the strength and durability of concrete restricts its use in higher-grade work. This paper presents a series of tests carried out on recycled coarse aggregate (RCA) and recycled coarse aggregate concrete (RCAC) and test results are compared with the NCA and parent concrete made from NCA. Tests were carried out as per IS code and concrete was prepared using a two-stage mixing approach in the concrete mix design. M30 concrete mix of four RCAC samples was tested at 28 days of curing and in comparison with parent concrete, it is found that on an average compressive strength is decreased by $12.89 \%$ at 28 days curing. Adhered mortar increases the porosity of the recycled aggregate and forms a weak zone between aggregate surface and mortar. In addition, test results showed the defects in recycled aggregate and helped to identify the area where concentration is necessary to improve the quality of recycled aggregate using six sigma DMAIC methodology. Total of 12 defects were found in the process and raw material. Statistical analysis was used to evaluate the performance of all the mix made with RCA.
\end{abstract}

Keywords- Recycle aggregate, Total quality management, Recycled aggregate concrete, Six sigma, Waste recycle.

\section{Introduction}

The efficient management of available resources and optimization of the process are essential issues in economic and environmental sustainability. Over the last few decades, there has been a substantial increase in economic activities that have contributed to the depletion of natural sources and the production of deposits (Ribeiro et al., 2016). The construction industry is one of the largest and it absorbs over $50 \%$ of natural resources and is also responsible for the production of more than $50 \%$ waste. 
International Journal of Mathematical, Engineering and Management Sciences

Vol. 5, No. 6, 1409-1419, 2020

https://doi.org/10.33889/IJMEMS.2020.5.6.104

The increasing demand for concrete required for infrastructural growth will eventually lead to a lack of natural aggregates. In many developing countries, such as India and China, the combination of concrete and brick or brick is used to build buildings. Thus, the demolishing of such kind of buildings generates huge waste. There is excessive construction and demolition (C\&D) waste being produced that causes environmental problems in developed countries (Radonjanin et al., 2013). Traditionally, the C\&D waste is disposed of in landfills, unnecessary occupying land. There is a huge demand for construction aggregates and is expected to grow yearly at a rate of $5.2 \%$ and is expected to be 5 billion metric tons by 2020 (Freedonia, 2012). Hence, the use of recycled aggregate is a feasible solution; it will protect the environment and diminution of natural aggregate sources.

Ingredients of concrete are cement, fine aggregate, coarse aggregate, water and possibly admixtures, additives or agents. Among these ingredients, the major volume is taken by fine aggregates and coarse aggregates. Conventionally, these aggregates have been available in the required quantities and at economical rates to serve the required purposes. However, it leads to environmental harm caused by quarries that produce NCA (Terro et al., 2013). Therefore, different countries are looking for alternatives to use recycled aggregate produced from $C \& D$ waste.
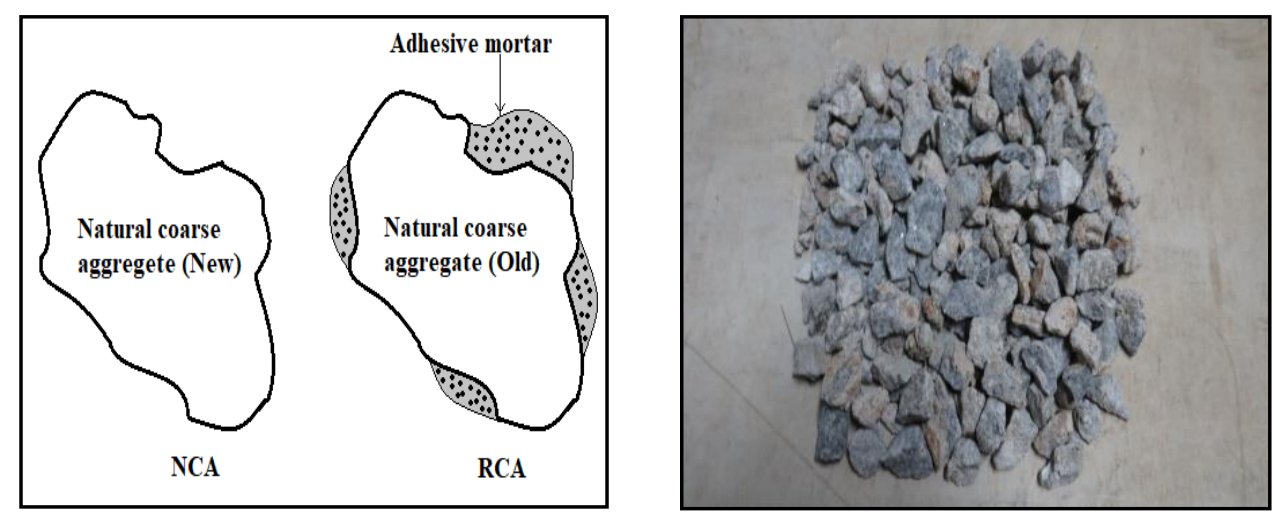

Figure 1. Recycled aggregate

Recycle aggregate as shown in Figure 1 can be obtained from various sources such as C\&D waste of demolished structures, laboratory crushed concrete, wastage at RMC plane, demolished concrete road pavement, and from construction waste recycling plant. Robinson et al. (2004) in the USA suggested incentives to inspire the use of recycled aggregate. Incentives are offered for the transportation of concrete waste and process it to get recycled aggregate. In Japan, the government has established the recycling law and has nominated materials that need to be controlled to promote and encourage the use of recycled aggregate concrete (Rao et al., 2007). Various research has been conducted in Taiwan, Hong Kong, and Japan to study the properties of recycled aggregate concrete to set the guidelines and limits for the use of recycled aggregate concrete in the construction industry. The use of statistical-based methods has emerged in various studies regarding the mix design of concrete (Kessal et al., 1996). Jafari et al. (2018) and Simon (2003) also used the statistical approach to optimize concrete mixtures proportions. Soudki and 
International Journal of Mathematical, Engineering and Management Sciences

Vol. 5, No. 6, 1409-1419, 2020

https://doi.org/10.33889/IJMEMS.2020.5.6.104

El-Salakawy (2001) used a full factorial experimental study to optimize a mix that could produce concrete that is less sensitive to hot climate temperature.

There is a need for efficient management of C \& D waste to reduce the consumption of natural sources and achieve sustainable construction. The use of recycled aggregate is a feasible solution. Six sigma has been implemented in the manufacturing industry to increase the efficiency of the production process, eliminate or minimize the defects in the process, improving qualities, reducing cost, and satisfying customers. Six sigma is a comprehensive improvement method used in business to achieve and sustain success. The method mainly focuses on statistical analysis, continuous improvement, and satisfaction of the customers needs (Papic et al., 2017). The benefit of the six sigma method includes identifying and eliminating defects, setting performance goals, enhancing value to customers, and achieving strategic objectives. Six sigma implementation uses a systematic process; a five-stage DMAIC methodology (Define, Measure, Analyze, Improve, and Control). Various researchers have used this methodology in their studies aiming for improvement in processes such as concrete block manufacturing plant, the sand-casting process for a flywheel manufacturing plant, and for quality evaluation of ready mix concrete plant (Kumaravadivel and Natarajan, 2013; Morales et al., 2016; Keshore et al., 2017). In the previous studies, research was focused on the quality improvement of RCA obtained from a single source using six sigma. This paper studies the effect of RCA obtained from different sources on the mechanical properties of RCAC. To study the effect, some samples of RCA are used as obtained from a source and some samples are treated. Samples of RCAC are prepared with 100\% replacement of NCA.

In this paper, the data analysis and result section are divided into five stages as per the DMAIC methodology. The first stage Define identifies the problem, response variables, and states the research goal. The Measure stage shows material used for the study, the procedure for concrete mixing, and specimen preparation for testing to measure the strength of RCA and RCAC. In Analyze stage, the material, and concrete specimen test results are shown and discussed. In the next, Improve stage, the defects are identified to improve the quality of RCA. Control is the last stage of the methodology where final response variables are observed and good quality of RCA among all samples is identified. The objective of the paper is to improve the process related to $\mathrm{C} \& \mathrm{D}$ waste through the implementation of six sigma and promote the use of RCA.

\section{Research Methodology}

The study has been carried out to examine the optimum concrete mix for concrete mix prepared with RCA obtain from C\&D wastes and laboratory crushed concrete. The overall framework structure is based on six sigma's DMAIC methodology. Figure 2 summarises the research design for the current study as a detailed methodology flowchart. 


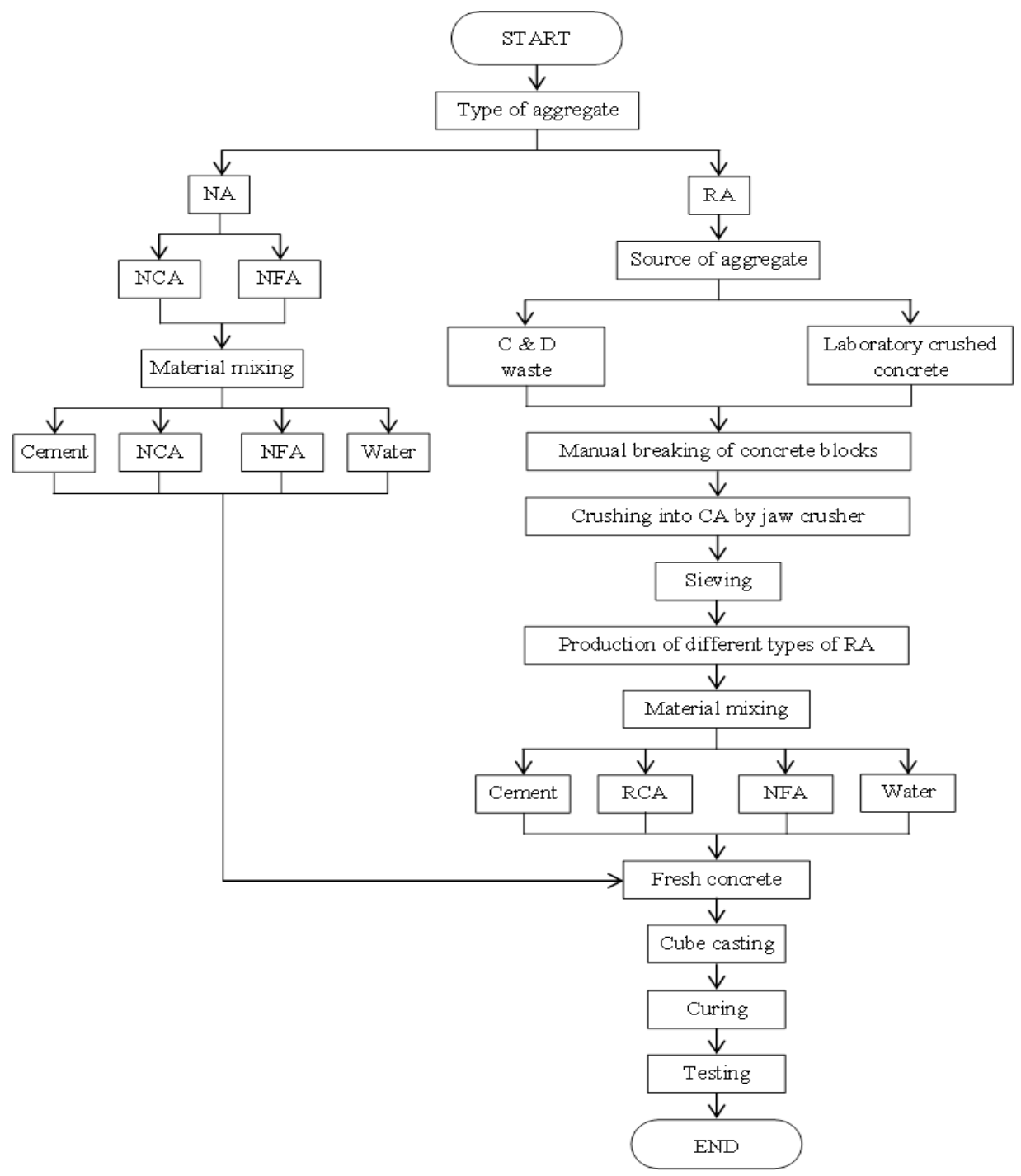

Figure 2. Process map

\section{Data Analysis and Results}

\subsection{Define Stage}

Define is the first stage of DMAIC methodology. In this stage, the problem is identified and response variables are set to study the problem. The stage also shows the necessity of this study.

\subsubsection{The Problem}

The application of recycled aggregate has initiated in construction projects in European, American, and Asian countries in recent decades. Recycled aggregate application in lower grade concrete work is also observed in India. However, because of recycled aggregate effect on workability, strength, and durability of concrete, its use in higher grade work is rarely observed 
International Journal of Mathematical, Engineering and Management Sciences

Vol. 5, No. 6, 1409-1419, 2020

https://doi.org/10.33889/IJMEMS.2020.5.6.104

(Babu et al., 2014). This study is carried out on M30 concrete made from different types of RCA and aims to find an optimal condition that would improve the quality of RCAC. The SIPOC shown in Table 1, is used to define the problem.

Table 1. SIPOC for the study

\begin{tabular}{|c|c|c|c|c|}
\hline Supplier & Inputs & Process & Output & Customer \\
\hline $\begin{array}{l}\text { Recycled aggregate } \\
\text { source: } \\
\text { 1.C\&D waste } \\
\text { 2. Laboratory crushed } \\
\text { concrete }\end{array}$ & $\begin{array}{l}\text { 1. Cement } \\
\text { 2. Natural fine } \\
\text { aggregate } \\
\text { 3. Coarse aggregate } \\
\text { a. NCA } \\
\text { b. RCA-1 } \\
\text { c. RCA-2 } \\
\text { d. RCA-3 } \\
\text { e. RCA-4 } \\
\text { 4. Water }\end{array}$ & $\begin{array}{l}\text { Figure } 2 \text { summarises the } \\
\text { research design for the } \\
\text { current study. It also } \\
\text { shows the detailed } \\
\text { process map of how } \\
\text { RCAC is produced for } \\
\text { the study of this } \\
\text { research. }\end{array}$ & Concrete & Researchers \\
\hline
\end{tabular}

\subsubsection{The Response Variables}

The properties of recycled aggregate such as water absorption, specific gravity, impact value, and abrasion value and the properties of RCAC like compressive strength, flexural strength, and split tensile strength along with durability properties decide the quality of concrete. For specific use of concrete in construction, these properties collectively or separately act as a response variable. Various response variables affecting the strength of RCAC are shown in Table 2. In this study, the compressive strength of concrete at 28 days of curing is considered as a final response variable. Concrete is strong in compression and the compressive strength test is the most indicative values of quality performance.

Table 2. Variables affecting the strength of RCAC

\begin{tabular}{|l|l|l|l|}
\hline \multicolumn{1}{|c|}{ Quality } & \multicolumn{1}{|c|}{ Proportions } & \multicolumn{1}{c|}{ Mixing } & \multicolumn{1}{c|}{ Testing } \\
\hline Source & Percentage of coarse RA & Mixing method & Curing \\
C \& D waste & Cement content & Mixing tools & Specimen type \\
Laboratory crushed & Cement type & Mixing approach & Specimen size \\
concrete & W/C ratio & Saturation condition of RCA & Testing method \\
Impurities in RA & Size of RA & Environmental condition & Operator \\
$\begin{array}{l}\text { Origin of RA } \\
\text { Type of RA }\end{array}$ & & Temperature & Age at testing time \\
Type of crusher & & & \\
\hline
\end{tabular}

\subsubsection{Research Goal}

The goal is to promote recycling and reuse of C\&D waste for sustainable construction and to maintain a green environment in India. This could be achieved by the use of recycled aggregate in concrete as a replacement to the natural aggregate. The initiative is already taken by introducing the use of recycled aggregate in recent IS-383-2016. Code allows the use of recycled aggregate up to $25 \%$ in plain concrete, $20 \%$ in up to M25 reinforced concrete, and $100 \%$ in lean concrete (IS 383:2016, 2016). 
International Journal of Mathematical, Engineering and Management Sciences

Vol. 5, No. 6, 1409-1419, 2020

https://doi.org/10.33889/IJMEMS.2020.5.6.104

\subsection{Measure Stage}

As the problem is defined in the previous stage, the Measure stage is to set the procedure and study the materials used for the concrete production for this study.

\subsubsection{Materials}

In this study, the raw materials used are cement, fine aggregate, water, and five different types of coarse aggregate. To obtain RCA waste concrete was brought in the laboratory and manually broken into small pieces and further crushed in a jaw crusher. Jaw crushed material is then sieved and aggregate pass through $20 \mathrm{~mm}$ and retained on $4.75 \mathrm{~mm}$ IS sieve used for experimentation. The materials and their properties with test results are explained in Analyze stage.

\subsubsection{Concrete Mix and Specimen Preparation}

With five different coarse aggregates and three different w/c ratios total of 15 , M30 mix were prepared for the study. Concrete is prepared by the guidelines given in IS-10262-2009 (IS 10262:2009, 2009). Two-stage mixing approach (TSMA) is used for the mixing of materials. Figure 3 illustrates the TSMA. Ten numbers of cubes of size 150x150x150 mm were cast for each mix to test the compressive strength. Test results are shown in the Analyze stage.

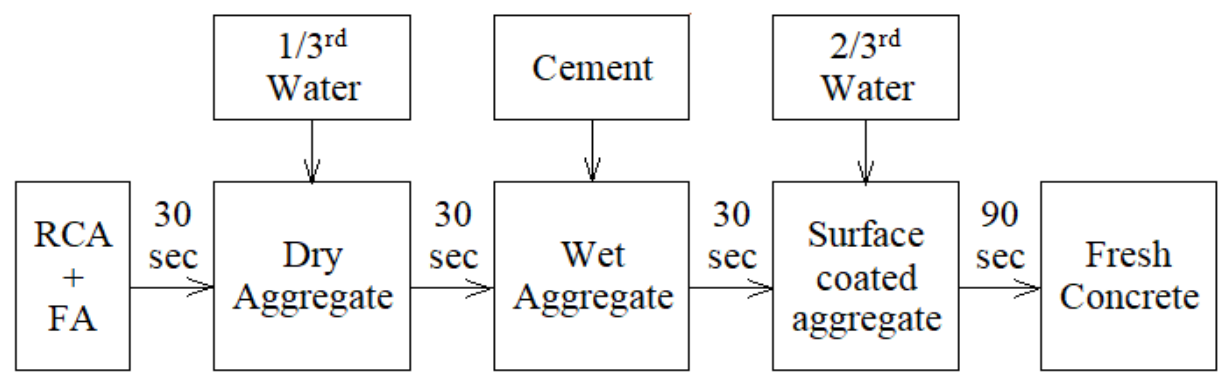

Figure 3. Two-stage mixing approach

\subsection{Analyze Stage}

\subsubsection{Recycled Coarse Aggregate (RCA)}

Total four types of RCA were used and they are termed as RCA-1, RCA-2, RCA-3, and RCA-4. RCA-1 was obtained from a concrete waste collected from a demolished twenty-five-year-old structure. By adopting a selective approach, only concrete members, i.e. foundation, column, beam, and slab C\&D waste was taken to extract RCA (Silva et al., 2014). RCA-2 is obtained from laboratory crushed concrete. The institute's material testing laboratory received various cubes from M20 to M45 under testing and consulting work. M25 and M30 are the most common grade of concrete which was received for testing. RCA-3 was selected from the mixture of the above two sources. While selecting, aggregate with a more adhered mortar and concrete pieces of size less than $20 \mathrm{~mm}$ are taken. The purpose of these selection criteria is to study the effect of adhered mortar on the properties of the RCA-3 sample. RCA- 4 was obtained by processing RCA in a rotating drum containing cast iron balls (Babu et al., 2014). The advantage of using this machine is that the mortar which is not as hard as the coarse aggregate will be broken down into smaller pieces as they fall over the machine and hit the steel balls. The aim is to remove adhered mortar attached to aggregate and use clean aggregate to produce a concrete specimen for testing. 
International Journal of Mathematical, Engineering and Management Sciences

Vol. 5, No. 6, 1409-1419, 2020

https://doi.org/10.33889/IJMEMS.2020.5.6.104

\subsubsection{Natural Coarse Aggregate (NCA)}

The NCA used here was of size $20 \mathrm{~mm}$ down and retained on $10 \mathrm{~mm}$. NCA was used to produce parent concrete to compare RCAC.

\subsubsection{Natural Fine Aggregate}

The aggregate passes through $4.75 \mathrm{~mm}$ IS sieve and retains on 75 -micron sieve is called fine aggregate. River sand has been used to carry out this study. Table 4 shows the test results of the fine aggregate.

\subsubsection{Cement}

Cement used was Ordinary Portland Cement 43 grade. Table 5 shows the test results of cement.

\subsubsection{Water}

Water actively contributes in chemical reaction with cement. The quantity of water used should be just sufficient for hydration and the suitable workability of concrete. For the present investigation, the potable water free of floating and dissolved impurities was used.

\subsubsection{Water/Cement Ratio}

Three water/cement ratio, $0.4,0.45$, and 0.5 are considered in this study.

Table 3. Test results of recycled aggregates and natural aggregate

\begin{tabular}{|c|l|c|c|c|c|c|}
\hline Sr. no. & Properties of Coarse Aggregate & NCA & RCA-1 & RCA-2 & RCA-3 & RCA-4 \\
\hline 1 & Water Absorption (\%) & 1.24 & 3.16 & 2.28 & 3.71 & 1.90 \\
\hline 2 & Sp. Gr. & 2.68 & 2.45 & 2.47 & 2.35 & 2.59 \\
\hline 3 & Impact value (\%) & 29.28 & 37.51 & 30.19 & 43.45 & 33.54 \\
\hline 4 & Abrasion Value (\%) & 30.69 & 48.72 & 40.00 & 56.73 & 34.79 \\
\hline \multirow{2}{*}{5} & Bulk Density & 1.34 & 1.22 & 1.44 & 1.27 \\
\cline { 2 - 7 } & 1. Loose (kg/lit) & 1.48 & 1.38 & 1.54 & 1.31 & 1.44 \\
\cline { 2 - 7 } & 2. Compacted (kg/lit) & 50.00 & 50.12 & 41.21 & 47.26 & 44.32 \\
\hline 6 & $\%$ voids & 7.71 & 7.68 & 7.05 & 7.68 & 7.11 \\
\hline 7 & Fineness modulus & & &
\end{tabular}

Table 4. Test result of fine aggregate

\begin{tabular}{|c|l|r|}
\hline Sr. No. & Properties of Fine Aggregate & Results \\
\hline 1 & Specific gravity & 2.62 \\
\hline 2 & Fineness modulus & 3.29 \\
\hline 3 & Water absorption & $0.88 \%$ \\
\hline 4 & Silt content & $2.42 \%$ \\
\hline 5 & Moisture content & Nil \\
\hline
\end{tabular}

Table 5. Test results of cement

\begin{tabular}{|c|l|l|}
\hline Sr. No. & Properties of cement & Result \\
\hline 1 & Specific gravity & 3.06 \\
\hline 2 & Normal consistency & $31 \%$ \\
\hline 3 & Initial setting time & 65 minutes \\
\hline 4 & Final setting time & 270 minutes \\
\hline 5 & Soundness of cement & $3 \mathrm{~mm}$ \\
\hline
\end{tabular}


International Journal of Mathematical, Engineering and Management Sciences

Vol. 5, No. 6, 1409-1419, 2020

https://doi.org/10.33889/IJMEMS.2020.5.6.104

Table 6. Test results of M30 mixes

\begin{tabular}{|c|l|c|c|c|}
\hline \multirow{2}{*}{ Sr. no. } & \multirow{2}{*}{ M30 mix concrete } & \multicolumn{3}{|c|}{ Compressive strength at 28 days curing $\left(\mathrm{N} / \mathrm{mm}^{2}\right)$} \\
\cline { 3 - 4 } & & $0.4 \mathrm{w} / \mathrm{c}$ ratio & $0.45 \mathrm{w} / \mathrm{c}$ ratio & $0.5 \mathrm{w} / \mathrm{c}$ ratio \\
\hline 1 & Parent concrete & 35.98 & 34.47 & 32.61 \\
\hline 2 & RCAC-1 & 33.57 & 31.17 & 30.14 \\
\hline 3 & RCAC-2 & 34.08 & 32.75 & 31.85 \\
\hline 4 & RCAC-3 & 27.31 & 25.63 & 23.26 \\
\hline 5 & RCAC-4 & 34.92 & 33.41 & 32.00 \\
\hline
\end{tabular}

\subsubsection{Discussion}

Table 3 illustrates the results of the test carried on all four samples of RCA and NCA. Water absorption should not be more than $2 \%$ and specific gravity should be in the range 2.5 to 3 to get good quality concrete from the aggregates. Similarly, the abrasion value should be less than $35 \%$ and impact value should be less than $45 \%$. From Table 3, it can be observed that only one sample of RCA; RCA-4 satisfies the above mention permissible limit. Table 3 also show fineness modulus for all five samples which range from 7.05 to 7.71 which means average size of aggregate is in between sieve number 7 and 8 in the sieve arrangement which is $10 \mathrm{~mm}$ to $12.5 \mathrm{~mm}$.

Table 6 illustrates the average value of the compressive strength of cubes for all fifteen M30 mixes. It is observed that RCAC-4 mix which is made by using RCA-4 sample shows better performance close to parent concrete made by using NCA.

\subsection{Improve Stage}

In this stage of DMAIC methodology, the defects in the process and materials are identified. The defects are identified based on the test conducted on materials and concrete cubes. Table 7 shows the defects in the process and raw materials. In ten defects factor, a total of 12 numbers of defects are found in the process and raw material.

Table 7. Defects in process and raw material

\begin{tabular}{|c|l|c|c|c|c|c|}
\hline Sr. No. & Defects Factor & Parent concrete & RCAC-1 & RCAC-2 & RCAC-3 & RCAC-4 \\
\hline 1 & Water Absorption & 0 & 1 & 1 & 1 & 0 \\
\hline 2 & Sp. Gr. & 0 & 1 & 1 & 1 & 0 \\
\hline 3 & Impact value & 0 & 0 & 0 & 1 & 0 \\
\hline 4 & Abrasion Value & 0 & 1 & 1 & 1 & 0 \\
\hline 5 & Bulk Density & 0 & 0 & 0 & 0 & 0 \\
\hline 6 & Fineness modulus & 0 & 0 & 0 & 0 & 0 \\
\hline 7 & Water temperature & 0 & 0 & 0 & 0 & 0 \\
\hline 8 & Compaction & 0 & 0 & 0 & 0 & 0 \\
\hline 9 & Cube dimension & 1 & 0 & 1 & 0 & 0 \\
\hline 10 & Rate of loading & 0 & 0 & 0 & 0 & 0 \\
\hline
\end{tabular}

\subsection{Control Stage}

\subsubsection{Observer Final Response Variable}

The final response variable in this study is the compressive strength of M30 concrete at 28 days of curing. This step helps sustain benefits and focuses on problems stay fixed for the long term. This stage deals with the design and analysis of the control system to maintain the quality level 
achieved in the analysis of this study. Figure 4 shows the statistical analysis of the compressive strength of M30 concrete. In Figure, Upper specific limit (USL) is fixed to $38.25 \mathrm{~N} / \mathrm{mm}^{2}$ and the lower specific limit (LSL) is fixed to $30 \mathrm{~N} / \mathrm{mm}^{2}$.

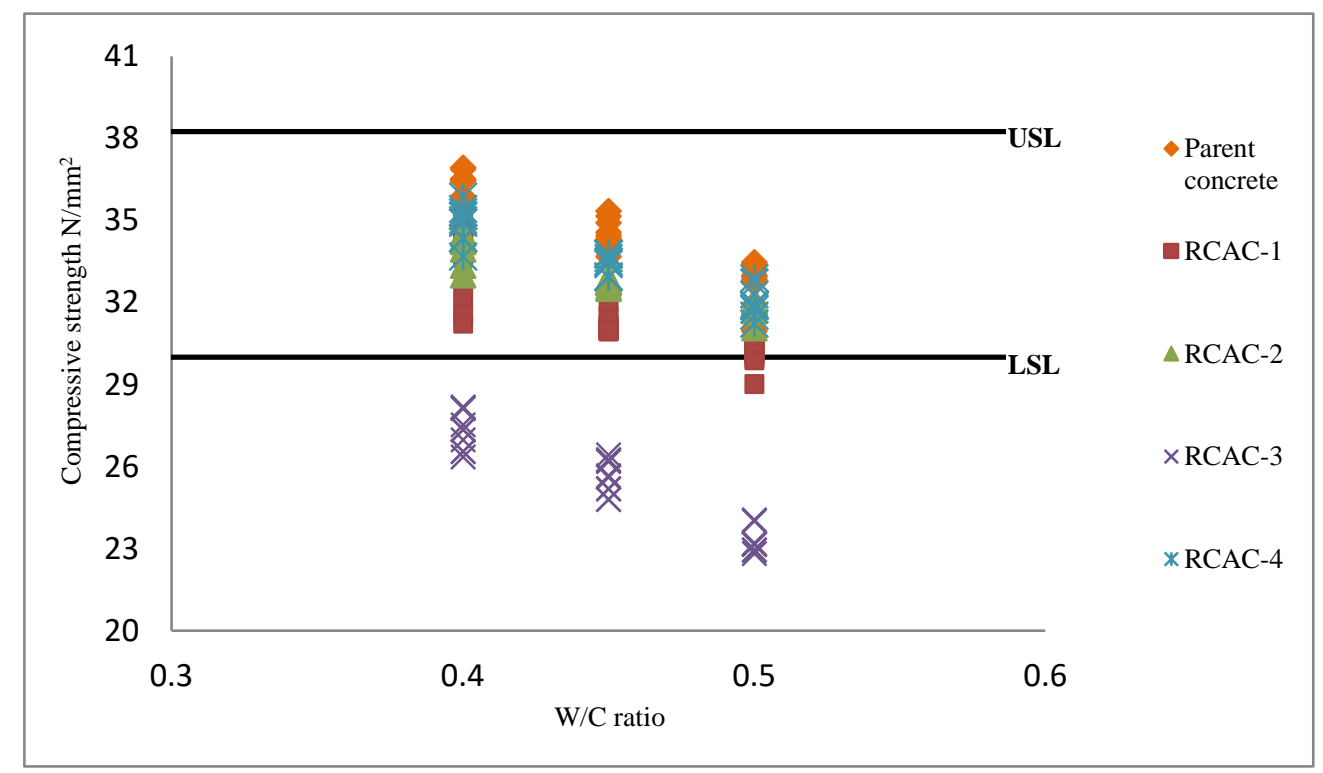

Figure 4. Statistical analysis of compressive strength of M30 concrete

\section{Conclusion}

From the study of all four samples of RCA, it is found that RCA-1 and RCA-3 show poor quality when compared to RCA-2 and RCA-4. The performance of RCA is affected mainly because of adhered mortar attached to the aggregate. Adhered mortar increases the porosity of the RCA and forms a weak zone between aggregate surface and mortar. The presence of adhered mortar leads to the development of micro-cracks during the crushing process and affects the strength of concrete.

Based on the study, a total of 12 defects were found. Out of 12 defects, ten were in material and two defects were in process. The defects in the material are easily avoidable by adopting RCA-4 which was treated to remove adhered mortar. Adhered mortar makes RCA weak compare to NCA. The defects in the process are also avoidable by having a skilled inspection at the execution level.

From the statistical analysis of the compressive strength of M30 concrete, it is found that RCAC4 falls under LSL for all three $\mathrm{w} / \mathrm{c}$ ratios. RCAC- $1 \mathrm{mix}$ with $0.5 \mathrm{w} / \mathrm{c}$ ratio is under LSL, whereas the same mix with 0.45 and $0.4 \mathrm{w} / \mathrm{c}$ ratio is within the range of LSL and USL. RCA-2 despite having defects in it, concrete made from this sample which is RCAC-2 performs well and falls within the range of LSL and USL for all three w/c ratios. This is due to the use of TSMA for the mixing of materials. As explained earlier, RCA-4 has no defects and it performs well, showing performance close to parent concrete. 
International Journal of Mathematical, Engineering and Management Sciences

Vol. 5, No. 6, 1409-1419, 2020

https://doi.org/10.33889/IJMEMS.2020.5.6.104

As the RCA-4 sample performs better among all RCA samples, the use of processed RCA is recommended in concrete instead of using RCA as obtained from the site. Quality of RCA can be improved by adopting mechanical methods to remove adhered mortar attached to the original aggregate. It is also recommended to use TSMA for the mixing of materials to get good quality concrete.

\section{Conflict of Interest}

The authors confirm that there is no conflict of interest to declare for this publication.

\section{Acknowledgement}

The authors acknowledge and express gratitude to the reviewer's constructive comments and valuable suggestions towards the improvement of the paper.

\section{Reference}

Babu, V.S., Mullick, A.K., Jain, K.K., \& Sing, P.K. (2014). Mechanical properties of high strength 385 concrete with recycled aggregate-influence of processing. Indian Concrete Journal, 88, 9-26.

Freedonia. (2012). World construction aggregates - industry study with forecasts for 2015 \& 2020. The Freedonia Group, 6.

IS 10262. (2009). Guidelines for concrete mix design proportioning. Bureau of Indian Standards, New Delhi, 1-21.

IS 383: 2016. (2016). Coarse and fine aggregate for concrete - specification (third revision). Indian Standard, third edit(January).

Jafari, K., Tabatabaeian, M., Joshaghani, A., \& Ozbakkaloglu, T. (2018). Optimizing the mixture design of polymer concrete: An experimental investigation. Construction and Building Materials, 167, 185-196.

Keshore, D., Joshi, N., \& Dwivedi, H.K. (2017). Implementation of six sigma for quality evaluation of RMC plant with dmaic methodology. International Journal of Engineering Research and Technology, 6(11), 153-157.

Kessal, M., Nkinamubanzi, P.C., Tagnit-Hamou, A., \& Aïtcin, P.C. (1996). Improving initial strength of a concrete made with type 20M cement. Cement, Concrete and Aggregates, 18(1), 49-54.

Kumaravadivel, A., \& Natarajan, U. (2013). Application of six-sigma DMAIC methodology to sandcasting process with response surface methodology. International Journal of Advanced Manufacturing Technology, 69(5-8), 1403-1420.

Morales, S.N., Ch, A.V., Torres-Argüelles, V., Martínez, E., \& Hernández, A. (2016). Six sigma improvement project in a concrete block plant. Construction Innovation, 16(4), 526-544.

Papic, L., Mladjenovic, M., Garcia, A.C., \& Aggrawal, D. (2017). Significant factors of the successful lean six-sigma implementation. International Journal of Mathematical, Engineering and Management Sciences, 2(2), 85-109.

Radonjanin, V., Malešev, M., Marinković, S., \& Al Malty, A.E.S. (2013). Green recycled aggregate concrete. Construction and Building Materials, 47, 1503-1511.

Rao, A., Jha, K.N., \& Misra, S. (2007). Use of aggregates from recycled construction and demolition waste in concrete. Resources, Conservation and Recycling, 50(1), 71-81. 
International Journal of Mathematical, Engineering and Management Sciences

Vol. 5, No. 6, 1409-1419, 2020

https://doi.org/10.33889/IJMEMS.2020.5.6.104

Rao, A., Jha, K.N., \& Misra, S. (2007). Use of aggregates from recycled construction and demolition waste in concrete. Resources, Conservation and Recycling, 50(1), 71-81.

Ribeiro, M., Gomes, M.C., \& Arantes, A. (2016). Application of lean methodology to improve sustainability in the construction and demolition waste industry. Adapting to Climate Change 2016, WATER, Waste and Other Local Infrastructure, 1-10. Retrieved from http://www.climatechangelisbon.com/

Robinson, G.R., Menzie, W.D., \& Hyun, H. (2004). Recycling of construction debris as aggregate in the Mid-Atlantic Region, USA. Resources, Conservation and Recycling, 42(3), 275-294.

Silva, R.V., De Brito, J., \& Dhir, R.K. (2014). Properties and composition of recycled aggregates from construction and demolition waste suitable for concrete production. Construction and Building Materials, 65, 201-217.

Simon, M.J. (2003). Concrete mixture optimization using statistical methods (No. FHWA-RD-03-060). United States. Federal Highway Administration. Office of Infrastructure Research and Development.

Soudki, K.A., El-Salakawy, E.F., \& Elkum, N.B. (2001). Full factorial optimization of concrete mix design for hot climates. Journal of Materials in Civil Engineering, 13(6), 427-433.

Terro, M., El-hawary, M., Al-fares, R., \& Goldstein, M. (2013). Utilization of six sigma in quality improvement of recycled aggregates concrete. Journal of Waste Management, 2013, 1-9. 